\title{
Interdependence and Independence in Escaping from Postfire Debris Flow Disaster
}

\author{
Ping Xu \\ University of Colorado Boulder
}

Current postfire debris flow strikes appear lacking an efficient warning system. People often think handling natural hazards is solely government responsibility. Many wildfires are caused by human ignition and have left vast landscapes vulnerable to postfire debris flows. This research discusses interdependence and independence in escaping from postfire debris flow strike, using case studies of Colorado and California. Identifying landform patterns of areas triggering debris flow and avoiding to reside in the prone zones is essential for survival. Education plays a crucial role in enduring natural hazards. Individuals maintaining responsibility, survival knowledge, and skills are contextualized in a safe community.

Keywords: Interdependence and Independence, Postfire Debris Flow, Self-Warning Method, Landform Patterns, Site Selection, Education

\section{INTRODUCTION}

The high temperatures and dry climate in the western United States have made frequent wildfires a major threat to many communities (Saunders, 2008). While wildfires themselves can cause extensive destruction, the landscapes that they desolate are left vulnerable to additional hazards, such as postfire debris flows. Erosions in fire-scar areas effectively accelerate and amplify the debris flow process. Recently vast fire scar zones have covered various and complex landforms. Many postfire debris flow events occur within areas that are not currently observed or mitigated by the government or scientific organizations. Evidently, many people unknowingly reside in disaster-prone zones.

Debris flows are regarded as one of the most dangerous natural hazards (Clark, 1987) and are often referred to by the media as "mudslides," "mudflows," or "flash floods." Debris flows begin with a dense combination of mud and stone, which increase in solidity, concentration, and size when proceeding downstream and finally develop into a fast-moving debris flow (Takahashi, 1991). During intense and heavy rain, a debris flow can gain great power, primarily when originating at higher elevations. Debris flows can reach speeds of up to $100 \mathrm{mph}$, and the initial debris walls can be up to 30 feet tall, quickly destroying homes and taking lives (King, 2018). There can be major and minor debris flow events. Major debris flows have often been recognized and mitigated by scientists and local governments (Li, 2004). The minor debris flows typically occur within local hills and can go unnoticed. All types of debris flows have the potential to be deadly. 
Debris flows following wildfires are common. According to Wells, the surface soil on a burned slope is loosely compacted and easily wet-able. This water-repellent layer is formed by burned organic molecules, which coat the soil particles and create a barrier for water to filter into the regolith. When it rains, pores between the loose soil begin to fill with water. The water in the pores puts downward pressure on the soil and causes a structural failure, excavating a rill. Surface water flows into the rill and runs downstream (Wells, 1987). For example, the debris flow disaster in Montecito occurred after the Thomas Fire burned 440 square miles. It created a "hydrophobic" layer in the ground - a kind of crust that repels water like glass (Burns, 2018). This layer accelerates the erosion process, affecting and strengthening debris flows.

The Rocky Mountain region contains landforms which provide abundant debris sources, such as steep slopes, exposed bedrock, sparse topsoil, and shallow tree roots. Extreme mountain weather patterns are also an essential factor in this area. Intense lightning storms can trigger forest fires, which can then spread rapidly over thousands of acres due to the Chinook winds and the highest peak gusts in the nation (NOAA, 2017). Meanwhile, the increasing residential population, dense development, and frequency of fires have changed these vulnerable mountainous systems, generating additional debris and accelerating erosion.

These abundant debris sources can cause debris flows when the area experiences consistent rainfall. From September $9^{\text {th }}$ to $15^{\text {th }}, 2013$, the Colorado Front Range experienced a week of heavy rain, which caused historic floods. The violent power of the floods destroyed homes and infrastructure, wiped out small towns, rerouted water channels, and took several lives. The most highly impacted areas experienced debris flows that damned water channels and caused additional flooding. The homes built within these debris flow impact zones exemplify a lack of site selection knowledge. While Colorado's mountain communities were still recovering from the postfire debris flow events of September 2013 (Aguilar, 2015), another tragedy occurred in Montecito, Santa Barbara, California.

\section{FIGURE 1 \\ CATASTROPHIC POSTFIRE DEBRIS FLOW EVENT IN MONTECITO, CA, 2018}

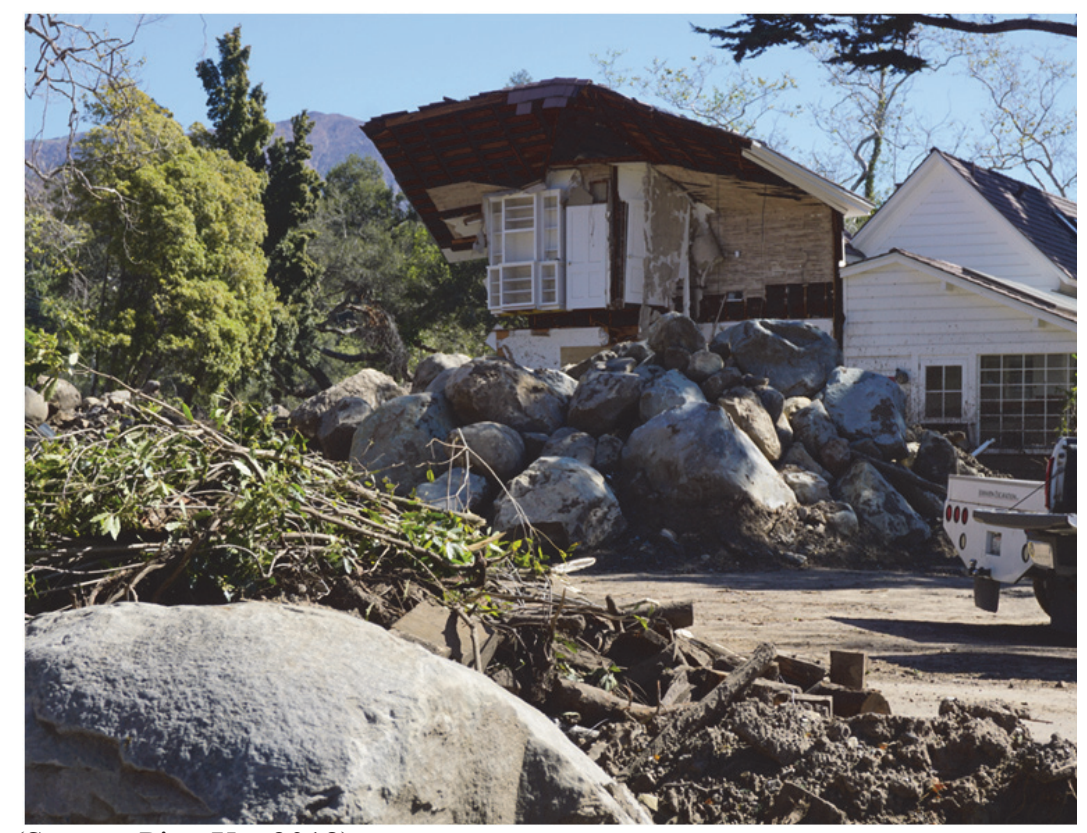

(Source: Ping Xu, 2018)

On January $9^{\text {th }}, 2018$, around 4 am, surging debris flows engulfed the majority of Montecito. The initial debris flow wall was 15 feet high in some locations. The flows caused at least 21 confirmed deaths, 
while over 150 people were hospitalized with various injuries. Additionally, the flows completely destroyed over 100 homes and damaged 300 residencies (Burns, 2018) (Figure 1). While such catastrophic events are rare occurrences, this is not the first time that this area has experienced a debris flow disaster. The geological conditions of Montecito provide abundant debris resources, which is one of the preconditions for debris flows. Almost all of Montecito and most of Santa Barbara are built on top of historical debris flow zones that occurred over the past 125,000 years (Burns, 2018).

When facing natural disasters, the general public has little knowledge of postfire debris flows, and mountain residents are not equipped to manage the impact. Some believe that handling natural disasters is solely the government's responsibility, while others ignore evacuation orders altogether. In our society, any independence is relevant to interdependence. This research discusses such relationships in connection to facing postfire debris flow strikes with inquiries such as: What is debris flow? When and where will a debris flow occur? How can civilians escape the strike and mitigate the damages?

\section{METHOD}

The research method includes the following components:

1) Discussing interdependence and independence when dealing with natural disasters by using two case studies of the historic 2013 Colorado floods and the 2018 postfire debris flows in Montecito, California. Awareness of human responsibility would be beneficial for future endurances of these increasing disasters.

2) Analyzing geomorphic studies and field investigations in the high impact zones of postfire debris flow in the Colorado Front Range and Montecito, California, using feng-shui as a clue. Feng-shui an ancient practice used to harmonize people with their environment. This analysis is utilized to identify the landform patterns of the areas susceptible to postfire debris flows and to develop the criteria for site selections avoiding areas at risk of debris flows.

3) Developing strategies for risk mitigation and exploring an adequate warning system/evacuation method for escaping from postfire debris flows. Raising public awareness and emphasizing individual responsibilities would improve collaboration with authorities to sustain mountain communities.

\section{INTERDEPENDENCE AND INDEPENDENCE}

\section{Independence and Responsibility}

People often think fire and postfire debris flow strikes are not preventable, blame nature, and then give up the spirit of independence. They attempt to believe that the hazard experienced has never happened before and will not occur again in their lifetime. With extreme climate patterns, there are many questions to be considered on this subject: Can fire and postfire debris flow be prevented? Are all postfire debris flows caused by nature? Should humans take responsibility for their role in these disasters?

Many people fantasize about living in forests and atop mountain peaks and asserting their freedom and independence, regardless of the risks associated with fire-prone zones. Some people favor areas besides lakes or at the confluence of two rivers, where there are often debris flow prone zones. With recent extreme weather patterns, these mountain hazards are likely to occur more often. In addition, more people are moving into these susceptible, hazardous zones, which aggravates the impacts of hazards further.

Meanwhile, many of these mountain residents often lack knowledge of postfire debris flows. During the debris flow of Montecito, most fatalities were residents who were sleeping when the disaster struck, while some were swept away when they attempted to venture outside (Mozingo, 2018). Only fifteen percent of the residents located within the mandatory evacuation area followed the evacuation notice (Serna, 2018). Such a fact indicates an unawareness of the severity of the residents' situation and the perceived vulnerability of their location. 
Fire strikes are often called "wildfires." However, over fifty percent of "wildfires" is caused by human ignition (Wildfires, 2016), particularly by campfires. Many tourists aim to explore their freedom and enjoy adventures outdoors, yet fail to think of the consequences that could come from the mismanagement of their campfires. These wildfire hazards can swiftly destroy hundreds of thousands of acres of forest, taking homes and lives. Even after the initial disaster is over, vast landscapes are left vulnerable to the deadly threat of postfire debris flows.

\section{MAP OF COLORADO WILDFIRES 2011-2016}

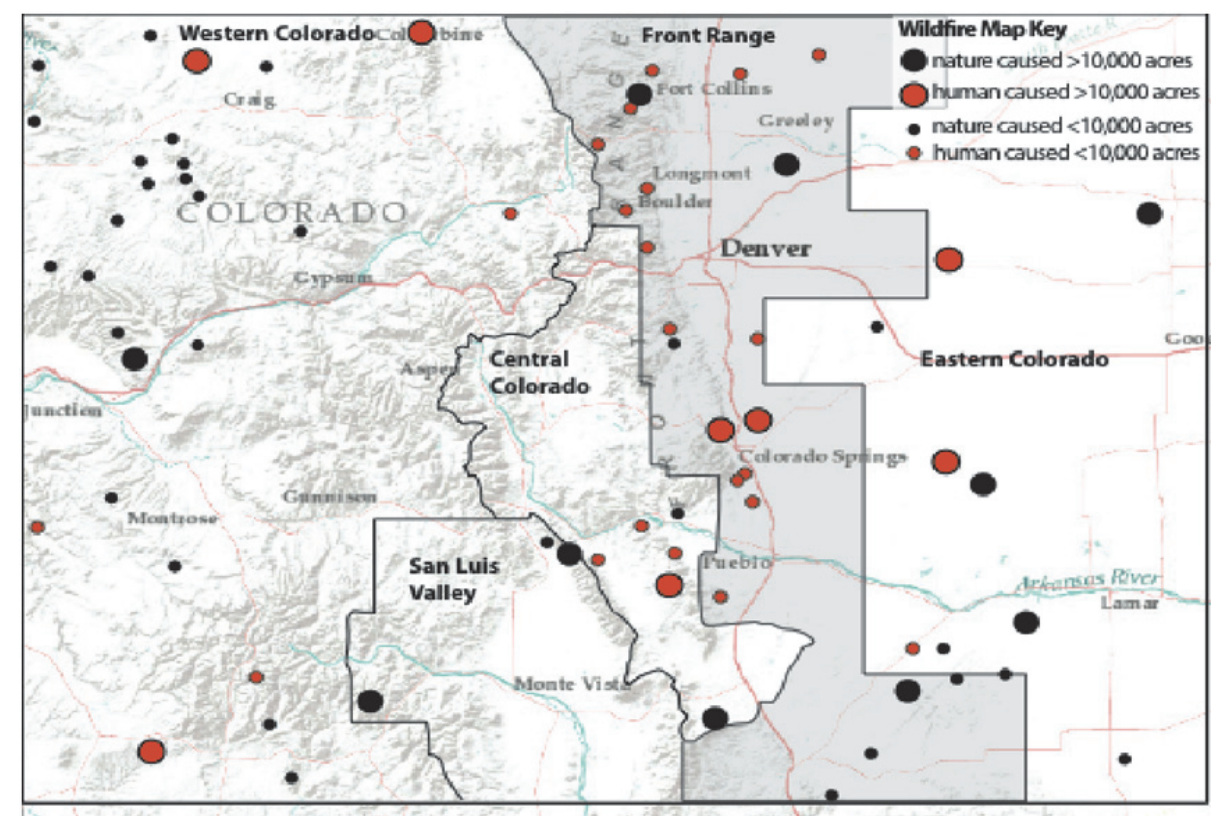

(Source: Ping Xu and Mackenzie Taylor)

Between 2011-2016, there were 108 fires in Colorado, resulting in over six-hundred thousand acres of burned land (Belknap, 2014; Wildfires, 2016). Within the Front Range area, sixty-four percent of these wildfires were human-caused (Figure 2). These fires triggered the 2013 Colorado postfire debris flows, and enhanced the possibility for future debris flow strikes (Xu, 2017). The Camp Fire that occurred in November of 2018 in California is the deadliest and most destructive blaze in California's history, charring more than 153,300 acres over 17 days. While drought conditions, strong winds, and warm weather were crucial factors in causing this devastating fire, a human-caused ignition has not been eliminated as a possibility (Johnson, 2018). Similarly, the Thomas Fire of December 2017 and January 2018 became one of the largest fires in California history (Burns, 2018). The Thomas Fire originated from an accidental construction site fire (Stolz, 2017), and led the catastrophic postfire debris flows in Montecito, CA. In fire and postfire debris flow events, humans can be victims, but they can also play major roles in initiating such disasters.

\section{Weakness of Education}

Current postfire debris flow strikes appear to lack an efficient warning system. During the Montecito debris flow event, the upper areas previously affected by the Thomas Fire were assigned as a mandatory evacuation zone. However, the lower areas were designated as the voluntary zone or outside of the evacuation zone altogether (Serna, 2018) (Figure 3). In debris flow strikes, it is typically plains of lower elevation which receive the highest impact. Thus, the lower plain had a higher number of fatalities in the Montecito debris flow event. Homes destroyed in high impact zones illustrate the failure of site selection. 
The architects, landscape architects, and urban planners involved in these site selections did not display enough knowledge on debris flow hazards. All issues have reflected the weakness of education on both fires and postfire debris flows. Ian McHarg indicates that modern architecture and landscape architecture education follow the dogma invented by famous architects without any effort to elicit the response of inhabitants to the existing environment. Indeed, science was resolutely excluded (McHarg, 1996). Even today, natural hazards are still not required in current architecture or landscape architecture curriculums, and scientific knowledge is only superficially considered.

\section{FIGURE 3 \\ MAP OF THE THOMAS FIRE SCAR ZONE AND HIGHEST IMPACT AREAS OF THE 2018 POSTFIRE DEBRIS FLOW EVENT, MONTECITO, CA}

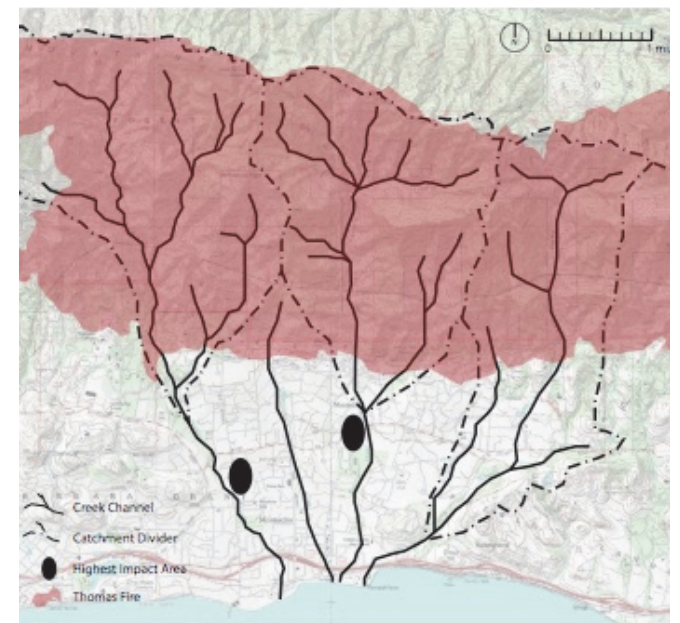

(Source: Ping Xu and Madden Kuljis, drafted using the Thomas Fire Interactive Map by Santa Barbra County, 2017)

Debris flows are not rare events; indeed, it is a common hazard in most mountainous regions. One example is the historic Big Thompson flood of 1976, one of Colorado's deadliest flash floods. The Big Thompson debris flow was caused by a year's worth of rainfall accumulating over four hours. Excessive amounts of water subsequently rushed down the mountain, gaining speed and collecting debris. Eventually, a twenty-foot tall wall of water and mud formed, flowing rapidly downstream. The debris flow resulted in a total of one hundred and forty-four deaths, desolating houses and destroying the canyon road - Highway 34 (Pohl, 2016). Although postfire debris flows are less researched, there are many books and article publications available on the subject. The book titled "Debris Flow/Avalanches: Process, Recognition \& Mitigation" (1987) by J. E. Costa and G. F. Wieczorek includes several articles on debris flows in Colorado and California. Particularly, the research of postfire debris flows by Wells, W. G. provides a pioneer work cited by many others. "Debris Flow" (1991) by Takahashi, T. is a scientific monograph of debris flow. With frequent fires and debris flow events occurring in recent decades, research publications have primarily increased. If architecture and planning education integrated with the scientific knowledge of fire and postfire debris flow, it could reduce hazard impacts and save millions in government funds, as well as many lives.

Sustainable design seeks a synthesis of social values, ecological balance, and economic prosperity $(\mathrm{Xu}, 2013)$. The integration of these three pillars should also be applied in dealing with fire and postfire debris flow events. Fires are one of the most significant hazards throughout the Rocky Mountains. In recent decades, increasingly frequent fires in Colorado have led many residents to doubt the following academic theory: Fire is an ecological system that plays a crucial role in shaping the natural landscape, and this system should not be limited (Wuerthner, 2006). Such a theory may influence park services to hesitate on banning campfires amongst mountains and forests, disregarding that campfires have been one of the leading causes of fire disasters. 
Colorado residents may align themselves more with Baker's conflicting theory: Fires should be investigated on a large regional scale, with hundreds of years of temporal understanding, including the increasing human impacts on and from the system. He argues that policies should be shaped to protect the people and the landscape. In the past, fires have been seen as manageable ecological processes in a resilient ecosystem. In the Rocky Mountains, however, this idea is no longer tenable (Baker, 2009). According to Baker, warming weather and expanding populations in mountain areas disrupt the natural cycle and substantially increase fire frequency and size. The Colorado Rockies have never experienced fire exclusion, as the Rocky Mountain landscape triggers fire events naturally. In the Rockies, there are few plants with seed banks to aid tree regeneration, and the dry weather also impacts the recovery time. Therefore, Colorado forests take a long time to recover from fires; many forests are still recovering from the large fires of the 19th century (Baker, 2009).

Burned trees release large amounts of carbon dioxide and can no longer filter pollutants or produce oxygen. Inhalation of smoke and ash from large wildfires creates serious health threats for the young and elderly, the ill, and those with heart or respiratory conditions (Climate Central, 2013). Fires damage wildlife habitat, water quality, and mature forests, and ultimately create extensive carbon dioxide pollution. Additionally, the extended periods of recovery on burned slope sides leave fire scar zones vulnerable to debris flow disasters. Considering the potential impacts on ecological balance and human health, fires in the wildland-urban interface should be immediately extinguished.

\section{Lack of Independence by Relying on Governments}

According to the author's experience in participating in three evacuations from fires and flash floods, public services and firefighters have done an outstanding job in warning, taking care of, and saving the lives of community members. Governments have spent substantial funds to aid residents recovering from the damages of disasters, as well as improve road conditions and drainage systems. In the years since the 2013 Front Range flood, Boulder's local government has spent approximately five-hundred million dollars in disaster recovery, with over three-hundred million dollars of this sum having been either secured or expected to be reimbursed (Lounsberry, 2018). These recovery efforts often involve reconstructing damaged homes on their original property.

Meanwhile, other residents who experienced overflows have repaired their homes with the reimbursements but have not addressed the drainage issues of their sites. By ignoring the site issues that have initiated damages, mountain-residents located in these high impact areas remain at risk for future debris flow disasters. Moreover, people depend on government funds to survive these disasters, which appear that preventing/fighting natural disasters is purely a government matter. These actions lacking independence not only increase government financial burdens but also reduce the likelihood of developing a long term plan for enduring the damages and effects of natural hazards.

The Big Elk Meadow, Colorado, was a high impact area of the 2013 floods. Located below a hillside that was affected by wildfire ten years ago, a house was destroyed by a 2013 postfire debris flow. In the summer of 2017, the author revisited the site. Surprisingly, a new house has already been constructed on the same site and within ten feet of the 2013 debris flow track (Figure 4). Past events have made it clear that the landform of this site has triggered debris flows during heavy rainfall. Thus, the new structure may face similar destruction by another debris flow strike. Policies that require damaged structures to be rebuilt on the same site can result in recurring damages for properties and rebuilt structures. 


\section{FIGURE 4 \\ NEW HOUSE CONSTRUCTED WITHIN TEN FEET OF THE 2013 DEBRIS TRACK}

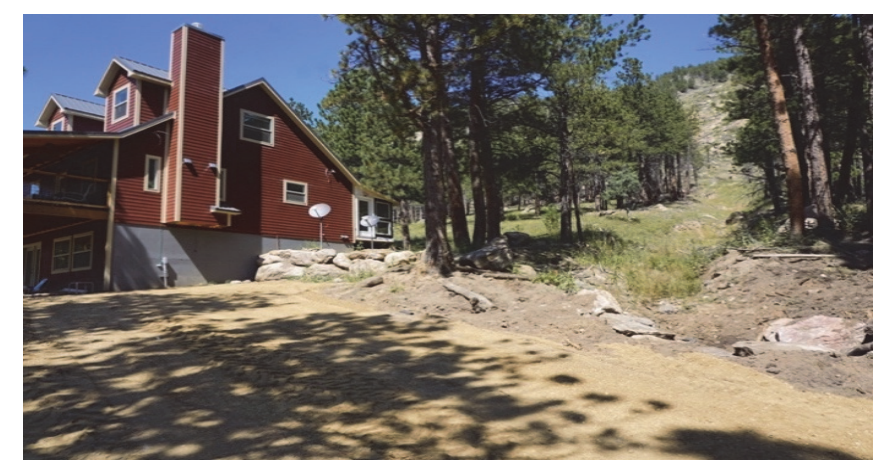

(Source: Ping Xu, 2017)

\section{WHERE: LANDFORM PATTERNS OF DEBRIS FLOW PRONE ZONES}

According to the author's field investigation in the impact areas of the postfire debris flows in the Colorado Front Range and Montecito, CA, certain landforms trigger debris flows. It is well known that high-intensity rainstorms trigger debris flows, but their spatial distribution appears to follow a pattern that has not been well researched (Lorente et al., 2002). Thus, it is crucial to research where the high impact areas are, and what landform patterns trigger debris flow. Avoiding residing in areas susceptible to debris flows would significantly reduce the risk of damages and save many lives.

The field investigations attempt to identify the landform patterns of the prone zones to debris flow, using feng-shui as a clue. The practice of feng-shui, particularly the principles of the form school, provides landform analysis of mountains, hills, water, and sites, to select favorable sites and avoid disaster. Feng-shui methods practice on multi-scales, large to small, looking from mountain ranges to cities, as well as homes and even graveyards. When dealing with the increasing hazards, some vernacular siting methods may provide wisdom (Xu, 2016a).

Discovering the landform criteria of debris flow prone zones would help to predict the potential impact areas in the mountains of Colorado and beyond. Based on geomorphic studies (Onda, 2004; Clark, 1987; and Reneau \& Dietrich, 1987) and the author's field investigations of Montecito, CA, and the Colorado debris flow zones, the discussion of landform patterns emphasizes three areas: the debris catchment, the debris flow track, and the debris flow fan/impact area.

The debris catchment includes the hillsides of basins and canyons, where debris and runoff accumulate, and debris flows are initiated. After a fire taking place in a debris catchment area, the available sources of debris increase (Figure 5). More importantly, wildfires change the structure of the soil, creating a waterproof layer. The accelerating erosion process alters the debris track to be straight and defined. This combination of environmental factors effectively accelerates and fuels debris flows, making them more powerful and worsening their overall impact. Feng-shui refers to the debris catchment area as the "dragon." In particular, feng-shui recommends avoiding any mountain basins containing debris (which are called the "sick dragon") or canyons with steep slopes and narrow channels (which are called the "violent dragon") (Xu, 1580). An example of a feng-shui identified "violent dragon" is the Big Thompson Canyon in Colorado. Several houses along this canyon were destroyed during the 2013 flood. 


\section{FIGURE 5 \\ INCREASED DEBRIS SOURCES WITHIN THE THOMAS FIRE SCAR ZONE IN THE DEBRIS CATCHMENT AREA, MONTECITO, CA}

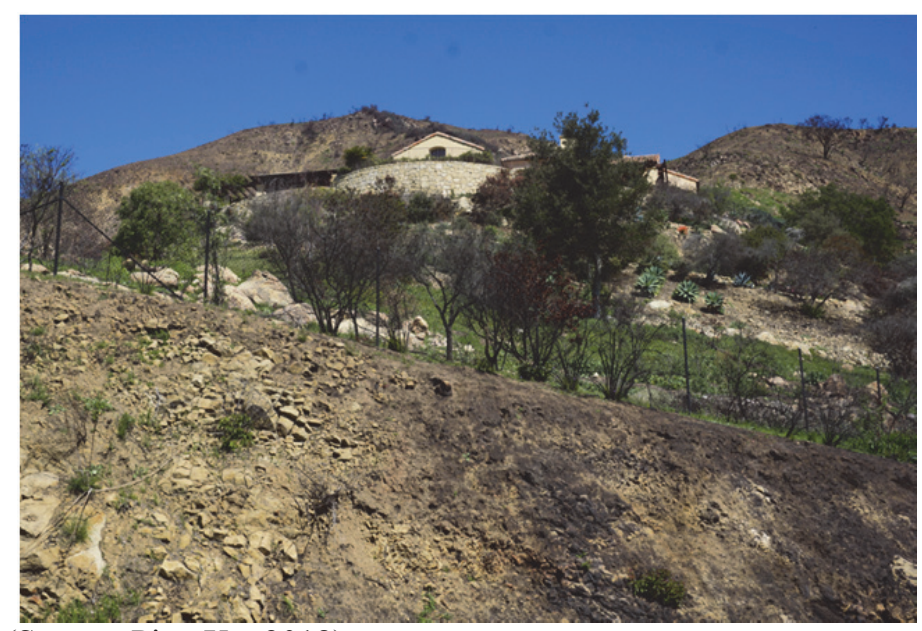

(Source: Ping Xu, 2018)

The second zone is a debris flow track, a water channel such as a gully, dry wash, or creek where debris events can develop. Flows generate their power by having a high volume of debris from a broad catchment pass through a narrow debris track. The debris tracks in Montecito, for example, are narrow, straight canyons and dry washes full of rocks and loose soil, making them prime candidates for powerful debris events. At these narrow channels, the debris can wash together and form small dams. During heavy rain, these dams eventually break and flush downhill, generating great power and developing into a full debris flow (Cui, 2012). According to feng-shui, a straight stream or river is evil, while a meandering stream or river is favorable. Any areas outside of meandering river curves should be avoided. Sites aligned with a dry wash or a narrow and straight channel should be avoided as well (Xu, 2016b). Such water channels are known as "hidden arrows" in feng-shui (Liu, 1986).

The final area is the debris flow fan, where the slope has dropped, and the debris is released. The debris flow was initiated in the basin area, where there was a rich debris source. In the basin area, the slope of the hillside is about $45 \%$. Once a slope starts to drop over $20 \%$, the debris flow takes a straight channel, altering the original creek track. Then finally, when the slope reaches less than $15 \%$, the flow releases the debris, water, and mud to the lower elevation plain, causing extensive destruction. Therefore, lower elevation plains are high impact areas.

The author's field investigations indicate that the high-risk areas of the 2013 floods present similar landform patterns to each other. The high impact areas include four significant zones. The first occurs where the slope suddenly declines by about $25 \%$, causing debris to release. The second is the zone on a hillside with a gulley/dry wash aligned to the site. The third area is the debris flow fan, where the dry wash or creek extends into lower elevations with slopes less than $15 \%$, and the debris is released with the most significant impact. The fourth area includes floodplains, especially at a confluence of two rivers or lakes, where the debris is released into water beds, which can block channels and cause flooding.

The most substantial impact areas in the 2013 Colorado floods were Jamestown and Drake, which both presented the same following landform patterns. First, the impact site, which has a slope of roughly $10 \%$, is located at a confluence area in the lower portion of a canyon, forming a receiving zone for debris flow. Second, a small creek typically originating several miles away flows to the site through a "violent" or "ominous" canyon, which has a zigzag shape. The hillsides of these canyons have a $25-35 \%$ slope, and their channels are narrow, facilitating the combination of water, mud, sand, rocks, and dead trees during a debris flow. The third is a river that points directly to the site, which is called the "water shooting heart" in feng-shui and can have the power to destroy homes during a flood. The final common landform pattern 
is a steep hill north of the site which experienced fires within a few years before the flood, leaving unstable soil and dead trees in its wake. These deposits develop into a debris flow that hits the site and feeds into the river during intense and heavy rain.

\section{HOW TO ESCAPE: SELF-WARNING METHOD}

People are drawn to the natural beauty and the diverse terrain of mountainous areas. However, the mountain residents often remain unaware of their potential locations in a debris prone zone. Thus, people living in these areas should perform a self-evaluation of their surrounding landforms. It is important to survey all landforms within the proximity, from mountain ranges and surrounding hills to local rivers and streams. Residents should be wary of being positioned within high impact zones, particularly in areas near a straight dry wash. If an evaluation proves a site to be within a potential debris prone zone, the resident should plan to relocate. If residents cannot relocate immediately, they should instead plan to vacate their property during the rainy season. It is safer to plan this absence as early as possible because of the abrupt and severe nature of debris flow events.

Postfire debris flows are prevalent during the rainy season - particularly during persistent periods of rainfall. The debris episodes can last for several hours, and flows can reach speeds of over 100mph with walls of debris rising to 30 feet (King, 2018). During the rainy season, residents remaining within postfire debris prone zones should be very attentive to the weather forecast and be prepared to follow any instructions or emergency evacuations administered to the public. Residents must also continue to stay vigilant after rainfall and not venture outside to witness the debris flow, as debris flows can occur consecutively at any time (Matjaž, 2003). Any site that has experienced a debris flow should be considered dangerous due to damaged construction and utilities. It is essential for residents to follow authoritative evacuation mandates and not go home until it is deemed officially safe.

Debris flows often produce thunderous sounds when passing through canyons (Chavez, 2018). If people who are hiking in canyons or valleys hear this sound, they must immediately climb to safety. Even if the weather does not indicate rainfall, precipitation elsewhere could trigger a debris flow capable of affecting other downstream areas. Debris flows are often too fast to escape.

When a debris flow reaches lower elevations, the flow often alters its track and will release debris into the areas below. Thus, mountain roads built alongside creeks and rivers within valleys at low elevations can be dangerous. One fundamental rule to evading a debris flow is to travel perpendicularly from its path. Debris flows can reach speeds of $100 \mathrm{mph}$, therefore making it impossible to escape them while traveling in the same direction. However, within mountains, alternative roads are usually unavailable. In the case that there are no other road options, it is imperative to abandon any motor vehicles and hike upwards and away from the flow to evade the debris.

Many historical floods have led to reshaped roads. The Big Thompson deadly debris flow of 1976 desolated houses and destroyed the canyon road, Highway 34 (Pohl, 2016). In recent years, Highway 34 has been rerouted. The new detour raises the road higher above the flood impact zone and allows people to escape to higher elevations (Johnson, 2017). This design upgrade will hopefully create a safer road through the canyon and increase the prospect of escaping a debris flow.

When escaping on foot, it is crucial to seek rocky based, stable terrain. Do not attempt to climb a muddy slope at the risk of setting off another landslide. Instead, escape to a tall neighboring hill. Tall landforms will provide protection from debris flows and can safely evade the $30 \mathrm{ft}$ walls of debris. Do not stand on the bank of a creek, because the debris flow will erode the bank. Additionally, do not climb trees along or within the bank; they can quickly be swept away and are often churned up into woodchips. Areas on the outside of creek curves should be avoided, as debris, mud, and water will follow their trajectory and launch to these sites. Avidly avoid flat areas at the bottom of the valley. Once a debris flow reaches these areas, the debris will be released and disperse, causing extensive destruction. 


\section{CONCLUSIONS}

Humans tend to have different attitudes toward independence and interdependence. Many people explore their "independence" by seeking the seclusion and adventure provided by outdoor settings; homeowners seek residences located within wooded areas or on high mountain peaks, while others pursue the wilderness through camping and lighting fires within forests. Meanwhile, others find independence through nonconformity and risk-taking, and will even jeopardize their safety to refuse evacuation orders. In these scenarios, people fail to realize their "independence" subconsciously relies on the assumption that society will secure their safety and wellbeing in the face of danger. On the other hand, people have conditioned themselves to think that natural disasters are out of human control. Even after experiencing a disaster event, there is a general belief and hope that these disasters will not occur again during the victims' lifetimes. In general, people resist acknowledging these issues and fail to relinquish their spirits to overcome these difficulties. Moreover, some people believe that preventing and fighting natural disasters is the sole responsibility of the government, and will wait for government funds to recover damages caused by hazards. In contrast, the people throughout history who have been able to sustain a balance between independence and interdependence could manage natural disasters and adapt to climate challenges, thus sustaining their society. As Darwin posited, "It is not the strongest of the species that survives, nor the most intelligent, but rather the one most adaptable to change" (Darwin, 1909).

Even though natural hazards are beyond human control, disastrous tragedies can also stem from design errors. Mistakes in design and site selection could lead to "nature's revenge." Buildings located in the prone zones of a postfire debris flow have been destroyed during heavy rainfall. Government funds have greatly helped people recover from the damages of natural disasters. For a long-term solution, in the future, the funds could emphasize assisting resident relocation from high impact zones to safer areas, rather than rebuild the destroyed homes at their original site. Additionally, residents repairing the damages to their homes should be required to improve their site conditions further. Without recognizing the site issues that had previously initiated damage, mountain communities located in these high impact areas remain at risk of debris flow in the future. Fisher states that we designed our way into disasters, but we can design the way out of them by understanding the nature of our errors. We cannot simply repeat these mistakes, as we have been doing over and over in recent decades (Fisher, 2013).

Identifying the landform patterns of the prone areas would assist authorities in predicting high impact zones, advance public knowledge and preparation, and inform the development of evacuation methods. There are four preconditions of postfire debris flows. First, the geological conditions present rich sources of debris, including rocks, rolling stones, loose sand and soil, and ancient debris flow deposits. Second, the area's landforms trigger debris flows. Debris flows will typically originate from steep slopes and basins in higher elevations, descend through narrow channels and canyons, and then destroy homes and take lives at the lower elevation plain. Third, the area has experienced a wildfire, particularly at a higher elevation, which accelerates and amplifies the debris flow process. The fourth precondition is that the area receives heavy and consistent rainfall.

The high impact areas are typically positioned downstream and include four major zones. The first occurs where the slope suddenly declines by about $25 \%$, causing a debris flow to release. The second occurs at a lower elevation with a slope of less than $15 \%$, where debris is released with the most significant impact. The third is in areas where the debris flows into rivers and lakes, especially at a confluence, which can block channels and cause flooding. The fourth high impact zone is on hillsides near or within a gulley/dry wash.

By identifying these criteria of landscape patterns, potential debris flow zones can be determined, and a warning method can be developed. These areas of concern can be mapped, which would effectively provide a basis for identifying hazard zones. Currently, any area affected by wildfires is well mapped by government institutions. These fire-scar areas, particularly those occurring at upper elevations of debris catchments, can cause catastrophic debris flows. Combining the fire-scar map with the potential debris

flow zone map will result in the impact zone map of postfire debris flows, with the highest impact areas located downstream from fire-scar zones. 
Postfire debris flows occur on fire-scar slopes. Therefore, controlling human-caused fires is essential. An open-fire ban zone should be established within the wildland-urban interface, where most of the population and economic interests are located. All fires in this area should be stopped immediately upon detection, including campfires, fireworks, debris or pile burning, and other open fires. In remote fireprone areas, populations should be limited so that large, infrequent fires can take their natural course and provide benefits to the ecological process.

Education is crucial in preventing excessive damages from natural disasters. In schools of architecture, landscape, planning, and environmental design, the curriculum should include courses related to managing natural hazards. Architects, planners, and developers should be particularly aware of debris flow issues when practicing in mountainous zones. Additionally, organizations in charge of evacuations should be trained and pass examinations to prove their knowledge on the subject. Park services should provide hazard evacuation plans to protect tourists' lives and avoid potential risks. Media should also promote scientific knowledge of fire and postfire debris flow events, in an effort to educate the general public on the topic. As individuals are prepared with proper education, the population as a whole will be better prepared to collaborate and endure natural disasters.

People living in mountainous terrain are encouraged to perform a self-evaluation of their surrounding landforms. It is important to survey all landforms within the proximity, from mountain ranges and surrounding hills to local rivers and streams. Be particularly aware of being aligned with a straight gully. If an evaluation proves a site to be within a potentially high impact area, residents should plan to relocate. It is especially imperative for the residents who live in the areas underneath a fire-scar zone and experience heavy and constant rainfall. If a debris flow occurs, residents should obey authorities' instructions indefinitely, as it is possible to trigger additional debris flows after the initial event. A critical strategy for escaping a debris flow is to move perpendicularly to the debris flow's direction. If there are no other available roads, it is crucial to abandon any motor vehicles, hike upwards perpendicularly to the flow, and seek rocky hilltop terrain. Additionally, do not climb trees along or within a bank; they can quickly be swept away. It is essential to avoid lower elevations, as these are considered high impact areas, and the areas outside of creek curves, as debris flows tend to alter their track, causing extensive destruction.

Fire and postfire debris flows are natural processes. They have happened consistently throughout history, and they will continue to occur in the future. However, once people move into a debris flow prone zone, they are under threat. To avoid being subjected to this natural disaster, the most effective strategy is to select building sites wisely. Although interdependence and independence are opposite aspects, they rely on each other and co-exist in a system. Every individual should realize their responsibilities within the society that they rely on for survival. A better understanding of the nature of postfire debris flows will not only increase survival rates but also enhance public collaboration with officials to make evacuations more successful and efficient. Individuals who maintain responsibility, survival knowledge, and skills are contextualized in a safe community.

\section{ACKNOWLEDGMENTS}

The IMPART grant and the UROP Award of the University of Colorado at Boulder support this research. These grants encourage student involvement in research. Particularly, the author would like to thank Rosa Borunda-Martinez, Sophie Burgess, and Tatum Wise for their help with editing this paper. 


\section{REFERENCES}

Aguilar, J. (2015). Two years later, 2013 Colorado floods remain a "nightmare" for some. Retrieved from http://www.denverpost.com/2015/09/12/two-years-later-2013-colorado-floods-remain-anightmare-for-some/

Baker, W. L. (2009). Fire Ecology in Rocky Mountain Landscapes. Washington, Covelo, London: Island Press.

Belknap, D. (2014). Map: Colorado Wildfires 2008-2012. The Coloradoan. Retrieved from www.coloradoan.com/story/news/local/wildfires/2014/04/17/map-colorado-wildfires-20082012/7833433

Burns, M. (2018). Deadly Montecito debris flow was rare event, but could happen again. The Santa Barbra Independent. Retrieved from https://www.independent.com/news/2018/jan/16/deadlymontecito-debris-flow-was-rare-event-could-/

Chavez, N. (2018). California mudslide survivors recall when the 'mud came in an instant'. CNN. Retrieved from https://www.cnn.com/2018/01/11/us/residents-describe-californiamudslide/index.html

Clark, G. M. (1987). Debris slide and debris flow historical events in the Appalachians south of the glacial border. Debris Flow/Avalanches: Process, Recognition, and Mitigation, ed J. E. Costa and G. F. Wieczorek. The Geological Society of America: Boulder, CO, pp. 125-138.

Climate Central. (2013). Report: Wildfires \& air pollution, a hidden hazard. Climate Central. Retrieved from http://www.climatecentral.org/news/ report-wildfires-and-air-pollution-a-hidden-hazard16651

Costa, J.E., \& Wieczorek, G.F. (1987). Debris flow/avalanches: Process, recognition, and mitigation. Boulder, CO: The Geological Society of America.

County of Santa Barbra. (2017). Thomas Fire interactive map. Retrieved from http://sbccaregis.maps.arcgis.com/apps/View/index.html?appid=236fabe29af0468aba330af399e6 dd66

Cui, P., Zhou, G.D., Zhu, X.H., \& Zhang, J.Q., (2012). Scale amplification of debris flows caused by cascading landslide dam failures. Geomorphology 182. Institute of Mountain Hazards and Environment: Chengdo, China, pp. 173-189.

Darwin, C. R. (1909). The Origin of Species. The Harvard Classics. New York: P.F. Collier \& Son, Vol. XI, 1909-14, 2001.

Fisher, T. (2013). Designing to Avoid Disaster: The Nature of Fracture-Critical Design. Routledge: Taylor \& Francis Group, New York and London.

Johnson, P. (2017). U.S. 34 opening Thursday from Loveland to Estes. Reporter Herald Loveland News. Retrieved from http://www.reporterherald.com/news/loveland-local-news/ci_31009099/u-s-34opening-thursday-from-loveland-estes

Johnson, K. (2018, November 15). What started the California fires? Experts track the blazes' origins. The New York Times. Retrieved from https://www.nytimes.com/2018/11/15/us/camp-fireparadise-cause.html

King, H. M. (2018). What is a debris flow? Geoscience News and Information. Retrieved from https://geology.com/articles/debris-flow/

Li, T. (2004). Mountain hazards in China. Mountain Geomorphology, ed. P. Owens and Olav Slaymaker, 219-241. London: Arnold.

Liu, J. (1986). The Collection of the Ancient Texts (reprinting 50 historical famous masterworks from 200 BC to 1600 AD). Taipei, Taiwan: Fu Li Publisher. (In Chinese).

Lorente, A., García-Ruiz, J.M., Beguería, S., \& Arnáez, J. (2002). Factors explaining the spatial distribution of hillslope debris flows: A case study in the Flysch sector of the central Spanish Pyrenees. Mountain Research and Development, 22(1), 32-29.

Lounsberry, S. (2018, August 8). Five years after flood, recovery nears $\$ 500 M$. Boulder Daily Camera. 
Matjaž, M., Fazarinc, R., Kocevar, M., Spacapan, I., \& Ribicic, M. (2003). The strung landslide with consecutive debris flows. Geophysical Research Abstracts. Retrieved from

https://www.researchgate.net/publication/236974242_The_Strug_Landslide_with_consecutive_d ebris flows

Mozingo, J., Mejia, B., \& Hamilton, M. (2018) Mud, darkness and destruction turned Montecito into death trap. Los Angeles Times. Retrieved from http://www.latimes.com/local/california/la-memontecito-mudslides-20180114-story.htm

McHarg, I. L. (1996). A Quest for Life. New York: John Wiley \& Son, Inc.

Onda, Y. (2004). Hillslope hydrology and mass movements in the Japanese Alps. Mountain Morphology. ed. P. N. Owens and O. Slaymaker, Arnold: London. pp. 153-164.

Pohl, J. (2016). 40 years later: Scores killed in Big Thompson Flood. The Coloradoan. Retrieved from https://www.coloradoan.com/story/news/2016/07/29/big-thompson-flood-killedscores $/ 87524858 /$

Reneau, S. L., \& Dietrich W. E. (1987). The importance of hollows in debris flow studies; examples from Marin County, California. Debris Flow/Avalanches: Process, Recognition \& Mitigation, ed. J. E. Costa and G. F. Wieczorek. Boulder, Colorado: The Geological Society of America. 165-179.

Saunders, et al. (2008, March). Hotter \& drier: The west's changed climate. Retrieved from https://www.nrdc.org/sites/default/files/west.pdf (Storm Events Database, n.d.)

Serna, J. (2018). County issued conflicting evacuation warnings before deadly Montecito mudslides. Los Angeles Times. Retrieved from http:/www.latimes.com/local/lanow/la-me-ln-montecito-mud20180123-story.html

Stolz, K. (2017, December 22). Thomas fire had two origins: Fresh revelation comes as residents sue Edison for allegedly starting the massive wildfire. Santa Barbara Independent. Retrieved from https://www.independent.com/news/2017/dec/22/thomas-fire-had-two-origins/.

Takahashi, T. (1991). Debris Flow. Brookfield, Vt. Published for the International Association for Hydraulic Research by A.A. Balkema.

U.S. Department of Commerce National Oceanic and Atmospheric Association (NOAA). (2017). Boulder Wind. Retrieved from https://www.esrl.noaa.gov/psd/boulder/wind.html

U.S. Department of Commerce National Oceanic and Atmospheric Association (NOAA). (2018). Flash floods and floods, a preparedness guide. The National Weather Service. Retrieved from https://www.weather.gov/pbz/floods

Wells, W. G. (1987). The effect of fire on the generation of debris flows in southern California. Debris Flow/Avalanches: Process, Recognition \& Mitigation, ed. J. E. Costa and G. F. Wieczorek. Boulder, Colorado: The Geological Society of America. 105-114.

Wildfires. (2016). Wildfires. Insurance Information Institute. Retrieved from http://www.iii.org/factstatistic/wildfires.

Wuerthner, G. (2006). Wildfire: A Century of Failed Forest Policy. Sausalito, CA.: The Foundation for Deep Ecology.

$\mathrm{Xu}, \mathrm{P}$. (2013). Applying systems philosophy: general models integrating architecture with landscape design to create a sustainable built environment in light of Feng-shui. The International Journal of Social Sustainability in Economic, Social and Cultural Context, 8(3), 159-174.

Xu, P. (2016a). Feng-shui - Ancient geodesign: Identifying predictive landform models of mountain flood impact zones. Journal of Digital Landscape Architecture [JoDLA], 1-2016.

Xu, P. (2016b). Feng-shui's "hidden arrow": A straight dry wash can trigger a debris/mudflow disaster. Academic Journal of Art \& Science, 1-12.

$\mathrm{Xu}, \mathrm{P}$. (2017). Fires and postfire debris/mudflows triggered by landforms in Colorado Front Range and the subsequent impact on and by humans. Journal of Digital Landscape Architecture, 2-2017.

Xu, S. (1580). Di Li Tian Ji Hui Yuan. Shanghai: The Shanghai Mountain House (In Chinese). 